\title{
Segmentasi Luka Diabetes Menggunakan Algoritma Contour Image Processing
}

\author{
Wien Fitrian Roshandri ${ }^{a, 1, *}$, Ema Utami ${ }^{b, 2}$, Agung Budi Prasetio ${ }^{\mathrm{b}, 3}$ \\ a STIK Muhammadiyah Pontianak, Jl. Sungai raya dalam, Pontianak 78391, Indonesia \\ ${ }^{\mathrm{b}}$ Universitas AMIKOM Yogyakarta, Jl. Ring road utara, Yogyakarta 55281, Indonesia \\ ${ }^{1}$ wien@stikmuhptk.ac.id*; ${ }^{2}$ ema.u@amikom.ac.id; ${ }^{3}$ agungbp.amikom.ac.id \\ * Penulis Korespondensi
}

\section{AbSTRAK}

Pengukuran luas luka pada penderita diabetes masih menggunakan cara manual dengan penggaris luka. Sedangkan penggaris yang ditempelkan keluka akan menjadi contaminated agent yang dapat menularkan infeksi pada penderita lain. Metode pengukuran digital diperlukan agar masalah tersebut bisa terselesaikan. Tetapi untuk memperjelas batas antara luka dan kulit diperlukan ketelitian dan akurasi yang tinggi. Untuk itu diperlukan metode pencitraan yang dapat melakukan segmentasi antara batas luka dan kulit paada pasien diabetes berbasis digital yang dinamakan digital planimetry. Penelitian ini menggunakan algoritma contour image processing dari nilai hue, saturation, value (HSV). kemudian melakukan iterasi sebanyak 5 kali dan filter gamma. Sehingga mendapatkan hasil segmentasi luka. Kesimpulan akhir dari penelitian ini adalah segementasi dengan metode ini belum dapat melakukan segementasi luka dengan baik dan diperlukan tambahan nilai masking yang lebih luas, akan tetapi hasil iterasi ke 5 mendapatkan error terkecil yaitu $0.002 \%$. Pencitraan digital yang dilakukan dalam penelitian ini dapat dikembangkan untuk menjadi alat ukur luas luka pasien diabetes berbasis digital.

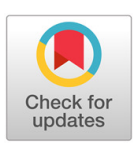

Kata Kunci Digital planimetry Image processing HSV

Luka diabetes Contour image

\section{Pendahuluan}

Diabates adalah salah satu penyakit berbahaya No.6 yang banyak menyebabkan kematian di Indonesia. Jumlah pederitanya berusia rentang dari $20-76$ tahun diperkirakan lebih dari 10.3 juta penderita [1]. Menurut International Diabetes Federation (IDF) tahun 2017, sekitar 425 juta orang menderita diabetes melitus, 123 juta orang diantaranya di atas usia 65 tahun dan 327 juta orang berusia diantara 20-64 tahun. Jumlah ini meningkat dari tahun 2015 yang sbesar 415 juta jiwa dan diperkirakan akan terus meningkat sebesar $48 \%$ yakni 629 juta jiwa di tahun 2019. Hasil riset kesehatan dasar prevalensi diabetes melitus di Indonesia pada penduduk umur lebih dari 15 tahun terjadi peningkatan $6.9 \%$ (2013) menjadi $8,5 \%$ (2018). Prevalensi diabetes yang terdiagnosis tertinggi terdapat di daerah DKI Jakarta (3.4\%) diikuti KALTIM (3.3\%). Penderita diabetes diperkirakan akan mengalami kejadian seumur hidup atau tidak tersembuhkan antara 15-25\% [2], bahkan ketika dapat disembuhkan maka tingkat untuk mengulang kembali luka diabetes sebesar 30$40 \%$ di tahun pertama kesembuhan [3]

Diabetes ulcer adalah luka yang disebabkan oleh komplikasi kronik dari diabetes melitus pada penderita diabetes. Pada umumnya ada dua jenis penyebab luka pada pasien diabetes, yaitu penyakit neuropati dan vaskularisasi [4] . Pengukuran luka diabates masih dilakukan dengan cara manual dengan langsung meletakan alat ukur/penggaris di luka pasien, hal ini dapat menyebabkan infeksi luka karena penggaris yang ditempelkan ke luka akan menjadi pengantar bakteri.

Luka yang diukur menggunakan cara manual ini dapat menyebabkan tidak akuratnya hasil ukur. Hasil ukur luka juga mempengaruhi metode pengobatan selanjutnya, besar kecil luka akan diperlakukan dengan metode pengobatan yang berbeda. Untuk itu diperlukan metode digitalisasi dan dokumentasi luas luka yang akurat. Pengkajian luka dengan pendekatan citra digital atau dikenal dengan istilah digital planimetry [5], [6], [7] . 
Penelitian yang dilakukan [8] menggunakan watershed segmentation dengan teknik flooding dan purning pada luka diabetes mendapatkan hasil akurasi segmentasi paling kecil sebesar $97.85 \%$ dah bahkan pada salah satu gambar terdapat akurasi $100 \%$. Namun dari penelitian mereka tersebut masih terbatas pada gambar luka yang tidak banyak variasi warna sehingga kemungkinan error memang sangat kecil.

Untuk melakukan segmentasi luka agar algoritma dapat membedakan dengan jelas batas kulit dan luka maka digunakan algoritma image processing dengan melakukan seleksi warna luka dari nilai hue, saturation, value (HSV) [9] yang diberikan, kemudian dikonversi menggunakan teknik contour image [10], [11], [12] sehingga nanti akan dirubah terlebih dahulu menjadi warna hitam putih. Melakukan perhitungan posisi luka dari seleksi nilai warna yang diberikan sebelumnya dan hasil akhir dari teknik segmentasi ini adalah akurasi luas luka dari beberapa nilai HSV yang diberikan sebagai input.

HSV mendefinisikan warna dalam terminologi Hue, Saturation dan Value [13]. Sebelum menentukan nilai HSV maka ditentukan nilai red, green, blue (RGB) terlebih dahulu sebagai koordinat warna [14]. Secara teknis warna RGB dipresentasikan dengan tiga komponen nilai. Setiap komponen nilai dapat bernilai 0 sampai 255 [15], [16] dimana $(0,0,0)$ dipreyeksikan sebagai warna hitam dan $(255,255,255)$ sebagai warna putih. RGB inilah disebut dengan colour space [17] yang dapat memproyeksikan warna utama sehingga menjadi warna yang additive. Beberapa contoh warna yang dihasilkan dari campuran RGB ini dapat dilihat pada Tabel 1.

Tabel 1. Konversi warna RGB

\begin{tabular}{ccccc}
\hline Warna & Nama & Hex & (R,G,B) & (H,S,V) \\
\cline { 2 - 5 } & Black & $\# 000000$ & $(0,0,0)$ & $(0,0,0)$ \\
& White & \#FFFFFF & $(255,255,255)$ & $(0,0,100)$ \\
& Red & \#FF0000 & $(255,0,0)$ & $(0,100,100)$ \\
& Lime & $\# 00$ FF00 & $(0,255,0)$ & $(120,100,100)$ \\
& Blue & \#0000FF & $(0,0,255)$ & $(240,100,100)$ \\
& Yellow & \#FFFF00 & $(255,255,0)$ & $(60,100,100)$ \\
\hline
\end{tabular}

Setelah nilai HSV didapatkan maka langkah selanjutmya adalah melakukan segmentasi warna. Segmentasi warna adalah sebuah proses pendekatan warna yang bekerja dengan menganalisis nilai warna dari tiap piksel dan membagi citra tersebut sesuai fitur yang diinginkan.

\section{Metode}

Sebelum menentukan segmentasi luka maka ada beberapa teknik yang diterapkan, diantaranya;

\subsection{Colour Space}

Seleksi warna yang paling umum digunakan adalah seleksi RGB yang direpensentasikan dengan warna merah (red), hijau (green) dan biru (blue). Didalam penelitian ini digunakan range warna merah dibagi menjadi 2 kategori yaitu : merah rendah (lower red) dan merah tinggi (upper red) yang dapat dilihat pada Tabel 2.

Tabel 2. Konversi tabel warna

\begin{tabular}{c|ccc}
\hline Kategori & Warna & $(\mathbf{R , G , B})$ & $(\mathbf{H , S , V})$ \\
\hline Lower red & & $179,0,0$ & $0,120,70$ \\
Upper red & & $255,42,0$ & $10,255,255$ \\
Lower yellow & & $255,242,204$ & $45,20,100$ \\
Upper yellow & & $255,217,102$ & $45,60,100$ \\
\hline
\end{tabular}

Warna RGB tersebut akan dikonversi terlebih dahulu kedalam warna HSV [18] dengan rumus sebagai berikut : 


$$
\begin{gathered}
H=\tan \left(\frac{3(G-B}{(R-G)+(R-B)}\right) \\
S=1-\frac{\min (R, G, B)}{v} \\
V=\frac{R+G+B}{3}
\end{gathered}
$$

Dengan menggunakan ide awal pada rumus diatas didapati masaalah jika saturation bernilai 0 maka hue tidak terdefinisi. Untuk itu cara kedua dapat menggunakan rumus sebagai berikut:

$$
\begin{aligned}
& r=\frac{R}{(R+G+B} \\
& g=\frac{G}{(R+G+B} \\
& b=\frac{B}{(R+G+B} \\
& C \max =\max (r, g, b) \\
& C \min =\min (r, g, b) \mathrm{s} \\
& \Delta=C \max -C \min \\
& \mathrm{h}= \begin{cases}60 \times\left(\frac{g-b}{\Delta} \bmod 6\right) & \text { jika } C \max =r \\
60 \times\left(\frac{b-r}{\Delta}+2\right) & \text { jika Cmax }=g \\
60 \times\left(\frac{r-g}{\Delta}+4\right) & \text { jika } C \max =b\end{cases} \\
& \mathrm{s}=\left\{\begin{array}{c}
0, \text { jika } C \max =0 \\
\frac{\Delta}{C \max }, \text { jika } C \max >0
\end{array}\right. \\
& \mathrm{v}=C \max
\end{aligned}
$$

Setelah melakukan konversi warna ke HSV dengan rumus yang telah di sebutkan, maka dilakukan konversi dengan rumus berikut.

$$
\begin{gathered}
H=h \times 2 \\
\mathrm{~S}=\frac{s}{255} \\
V=\frac{v}{255} \\
m=(H, S, V)
\end{gathered}
$$

Pada rumus tersebut didapat nilai $\mathrm{m}$ adalah nilai masking yang digunakan. Rumus tersebut berlaku untuk setiap array mask yang di buat dalam penelitian ini.

\subsection{Segmentasi Warna Luka}

Segmentasi gambar adalah proses yang digunakan untuk mencari lokasi objek dan batas (misalnya, garis atau kurva) pada gambar [19]. Selanjutnya, dapat didefinisikan sebagai proses pelabelan setiap piksel dalam sebuah gambar, di mana semua piksel memiliki label yang sama berbagi karakteristik visual tertentu. Segmentasi menggunakan informasi lokal dalam gambar digital untuk menghitung segmentasi terbaik, seperti informasi warna yang digunakan untuk membuat histogram atau informasi yang menunjukkan tepi, batas, atau informasi tekstur. 
Segmentasi dilakukan agar algoritma dapat membedakan warna antara luka dan kulit [20]. Pada Tabel 2 ditampilkan warna segmentasi HSV yang digunakan. Pada Gambar 1 luka diabetes akan menemukan perbedaan warna yang lebih mencolok daripada warna kulit.

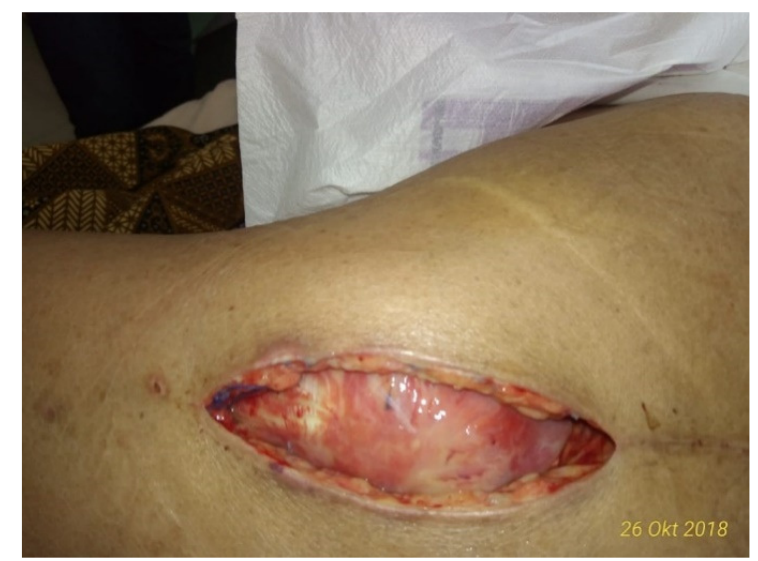

Gambar 1. Segmentasi warna luka dan kulit

Dengan didapatnya range warna HSV pada metode sebelumnya maka pendekatan segmentasi pada luka seperti yang terlihat pada Gambar. 1 dapat dilakukan. Algoritma akan menemukan luka sesuai dengan kode warna HSV yang sudah di tentukan sebelumnya yaitu lower dan upper theresholds [21].

\subsection{Konversi HSV ke Contour Image.}

Hasil range warna yang didapat setelah segmentasi akan di rubah ke warna kedalam HSV [22], [23] terlebih dahlu seperti Gambar 2 dan black and white terlebih dahulu seperti terlihat pada Gambar. 3.

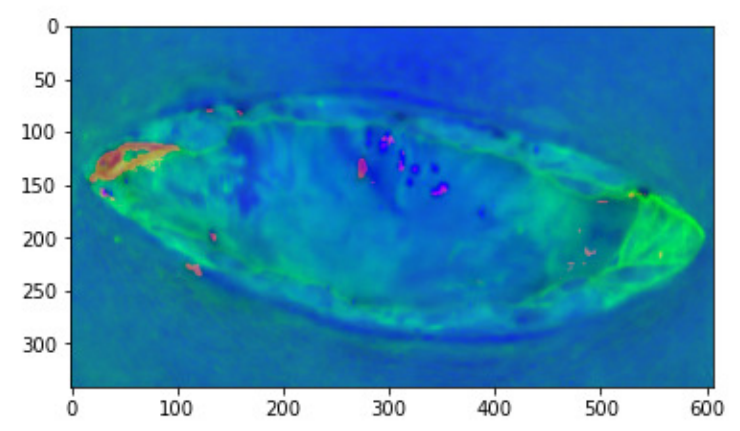

Gambar 2. Konversi luka ke $H S V$

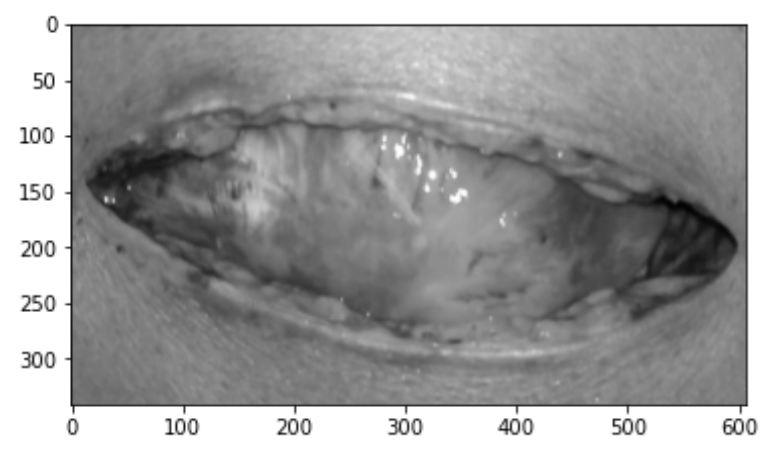

Gambar 3. Konversi luka ke Gray Map 
Hal ini dilakukan untuk memperjelas batas segmentasi dan mendapatkan area mask yang akan digunakan untuk lower dan upper red sebagai masking yang nantinya menjadi dasar nilai untuk merepresantasikan koordinat luka dan melakukan perhitungan luas luka.

\subsection{Ploting RGB dan HSV menjadi 3D}

Untuk mempermudah menentukan colour space yang akan digunakan maka kita dapat melakukan plotting colour RGB kedalam 3D dapat dilihat pada Gambar 4 dan plotting HSV pada Gambar 5.

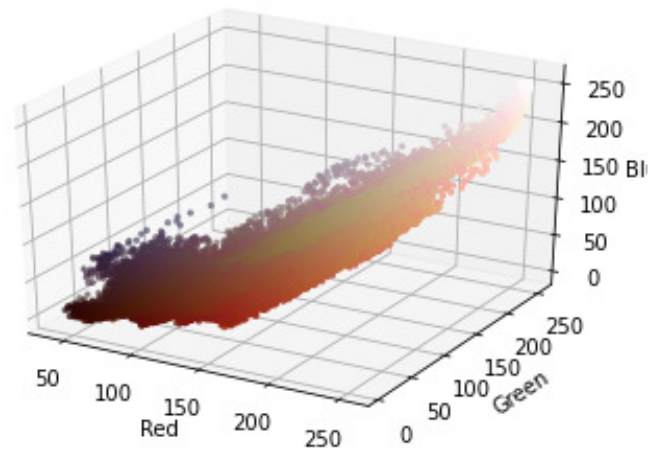

Gambar 4. Plotting image 3D RGB

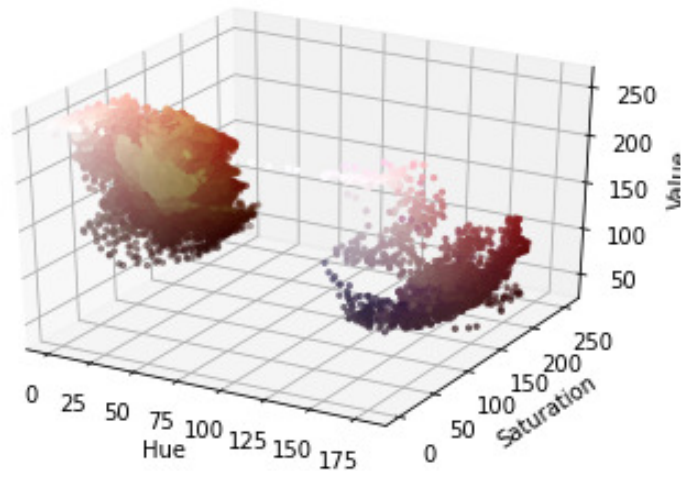

Gambar 5. Plotting image 3D HSV

\section{Hasil dan Pembahasan}

Berdasarkan penelitian yang dilakukan Jawahar [24] dengan metode yang sama, belum menunjukan hasil yang baik dalam mendapatkan color space dari nilai HSV dan hanya melakukan satu kali masking sehingga akan mendapatkan hasil segmentasi luka yang kurang maksimal yang dapat dilihat pada Gambar 6.
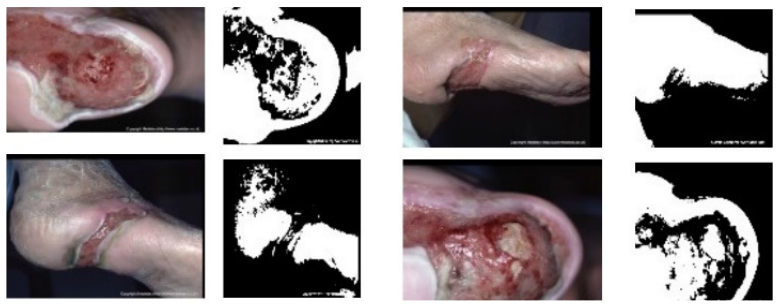

Gambar 6. Hasil penelitian Jawahar

Sedangkan untuk penlitian yang dilakukan menggunakan 6 buah sample gambar luka yang berbeda dan difoto langsung pada luka pasien diabetes dapat dilihat pada Gambar 7. Posisi pengambilan gambar luka dilakukan dengan derajat kemiringan $80^{\circ}$ hingga $90^{\circ}$ dengan iluminasi cahaya sebesar 900 lux, camera yang digunakan dalam pengukuran luka mempunyai resolusi $5 \mathrm{Mp}$ dan kerapatan setiap 1 inch PPI. Gambar yang akan di hasilkan dengan ukuran $=2580 \times 2048=$ 
5,283,840 pixels dan aspect ratio 1.26 dan dalam posisi landscape. Estimasi hasil akhir ukuran gambar jika dalam format jpg 24bit/pixel sebanyak $100 \%$ uncompressed maka didapat rata-rata 1,08 Mb. Melakukan dua kali masking dan menggunakan lima kali iterasi dan gamma value. Perbedaan penelitian sebelumnya dapat dilihat pada Tabel 3 .

Tabel 3. Perbedaan penelitian

\begin{tabular}{ccccc}
\hline Peneliti & Metode & Iterasi & Gamma & error \\
\hline Jawahar [24] & HSV & 0 & 0 & 0.06 \\
Elmogy [25] & CAD & 0 & 0 & 0.06 \\
Li [26] & HSV & 10 & 0 & 0.24 \\
Rother [27] & Grabcut & 10 & 5 & - \\
\hline
\end{tabular}

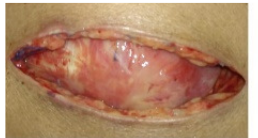

(a)

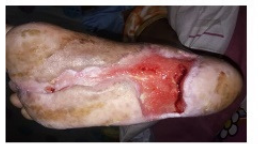

(d)

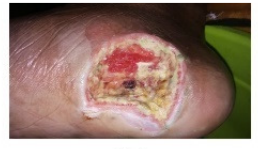

(b)

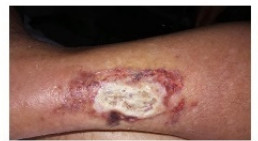

(e)

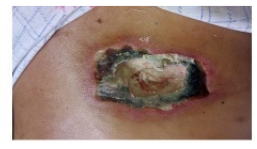

(c)

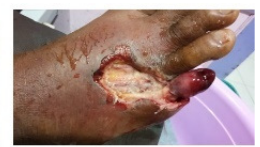

(f)

Gambar 7. Sample luka

Kemudian gambar dilakukan konversi dari RGB ke BGR dan HSV dapat dilihat pada Gambar 7. Hal ini dilakuakn agar memudahkan melakukan masking dan segmentasi warna.

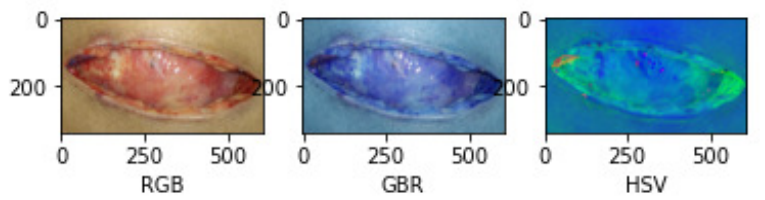

Gambar 8. Konversi warna RGB, BGR, HSV

Setelah melakukan konversi warna, langkah selanjutnya adalah melakukan proses mapping contour dan masking awal warna high red dan lower red, seperti terlihat pada Gambar 8.

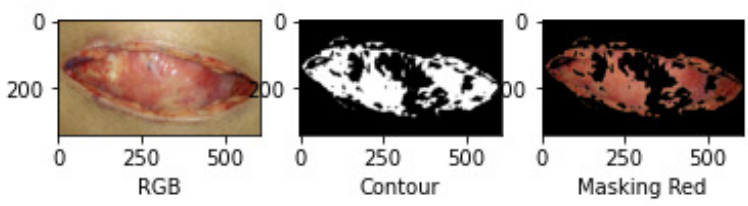

Gambar 9. Contour dan masking red

Hasil segmentasi 6 luka yang dilakukan dengan set atribut jumlah iterasi 5, cluster 5 dan gama 5 dapat dilihat pada Tabel 3. Iterasi dilakukan sebanyak 5 kali dengan mempertimbangkan hasil yang didapat sudah baik. Pengulangan iterasi dilakukan agar hasil akhir dari masking mendapat error yang lebih sedikit. Hal ini terlihat pada Tabel 4 bahwa semakin banyak melakukan iterasi maka error yang didapat akan semakin sedikit. Logika awal dari melakukan iterasi adalah sebagai berikut :

var i, a:=0

for i from 1 to 5

\{

$a:=a+i$

\}

print a 
Pada data (a) didapati nilai awal adalah 0.219 kemudian dilakukan iterasi kedua dengan nilai awal adalah data (a) sehingga nilai dari iterasi kedua menjadi 0.016 dan begitu seterusnya hingga dilakukan pengulangan 5 iterasi.

Tabel 4. Error dan response time pada iterasi

\begin{tabular}{ccccccc}
\hline \multirow{2}{*}{ data } & \multicolumn{9}{c}{ Error Iterasi dalam \% } & \multirow{2}{*}{ Time } \\
\cline { 2 - 6 } & $\mathbf{1}$ & $\mathbf{2}$ & $\mathbf{3}$ & $\mathbf{4}$ & $\mathbf{5}$ & (s) \\
\hline (a) & 0.219 & 0.016 & 0.009 & 0.005 & 0.004 & 51.98 \\
$(b)$ & 0.053 & 0.009 & 0.004 & 0.0007 & 0.0009 & 165.36 \\
$(c)$ & 0.079 & 0.019 & 0.025 & 0.032 & 0.008 & 179.72 \\
$(d)$ & 0.075 & 0.017 & 0.004 & 0.0019 & 0.0016 & 161.23 \\
$(e)$ & 0.029 & 0.003 & 0.001 & 0.0008 & 0.0002 & 161.91 \\
$(f)$ & 0.040 & 0.095 & 0.053 & 0.006 & 0.002 & 167.91 \\
\hline
\end{tabular}

Berdasarkan hasil pada Tabel 3 diatas maka grafik error dan response time pada iterasi dapat terlihat pada Gambar 9. Hasil akhir masking dalam menentukan batas luka dapat dilihat pada Gambar 10 .

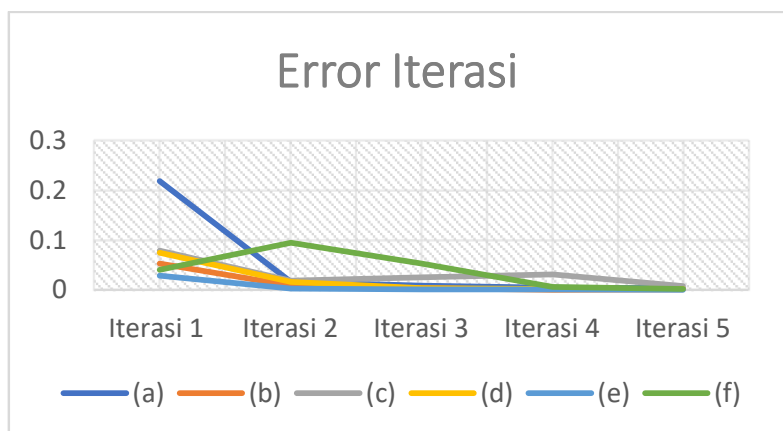

Gambar 10. Grafik error pada iterasi
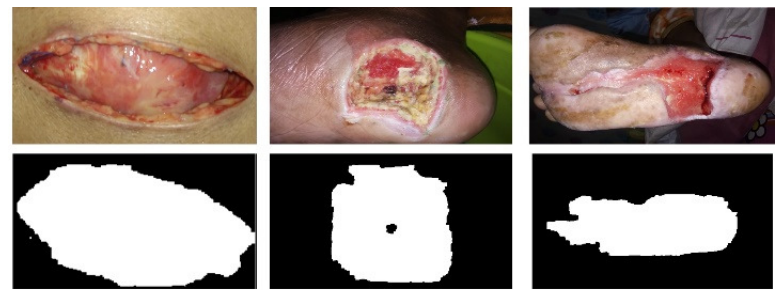

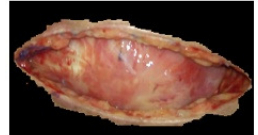

(a)

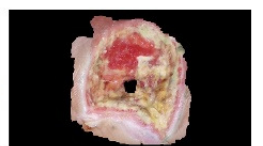

(b)
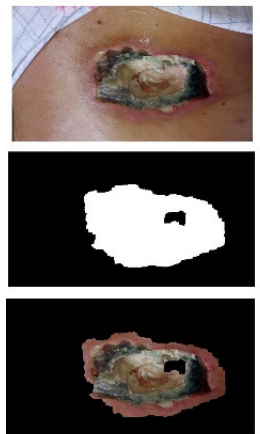

(d)
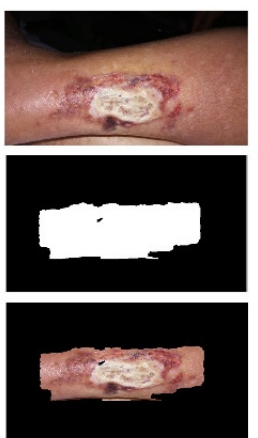

(e)

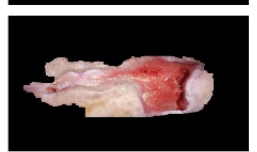

(c)
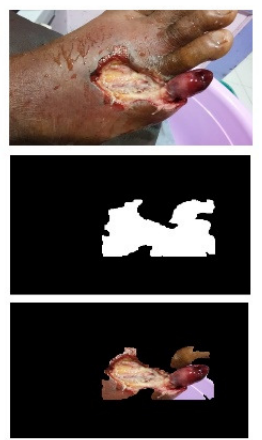

(f)

Gambar 11. Hasil akhir masking 
Hasil pada Gambar 10 pada (a) memperlihatkan gambar asli dari luka. Kemudian dilakukan pemprosesan algoritma masking iterasi sebanyak 5 kali sehingga didapat hasil masking dengan error yang terkecil. Hasil akhir segmentasi dapat dilihat pada gambar terakhir pada setiap point di Gambar 10.

\section{Kesimpulan}

Penggunaan colour space berdasarkan identifikasi nilai pixel warna yang dilakukan di penelitian ini menunjukan hasil yang sudah baik yang dapat di lihat pada jumlah error yang relatif kecil dan terkecil adalah $0.002 \%$. Waktu yang diperlukan untuk mengolah iterasi paling kecil adalah 51.98 detik, berdasarakan analisa bahwa semakin besar ukuran gambar yang diproses maka diperlukan waktu yang lebih lama, untuk itu diperlukan pengambilan gambar dengan fokus ke luka saja agar response time lebih kecil. Memang sangat sulit membedakan antara warna kulit dan luka yang hampir memiliki rentang nilai warna pixel sama. Hal ini berbeda dengan melakukan segmentasi dengan background yang contras. Warna kulit pasien diabetes juga bervariasi dan algortima harus dapat membedakan dengan jelas warna kulit dan luka.

Beberapa warna tidak dapat dikenal di luka seperti warna hitam pada tengah luka dan bukan di luar luka, sehingga algoritma membaca warna tersebut adalah warna backgorund dan bukan warna luka. Untuk penelitian selanjutnya diharapkan dapat meneruskan segmentasi luka ini dengan menambahkan seleksi filter seperti gaussian delasi maupun erosi untuk memperhalus hasil segmentasi batas luka dan kulit.

\section{Deklarasi}

Kontribusi Penulis. Semua penulis berkontrbusi secara bersama-sama dengan kontributor utama dalam artikel ini. Semua penulis membaca dan menyetujui versi akhir dari artikel yang diajukan.

Pernyataan Sponsor. Tidak ada penulis yang menerima dana atau hibah dari lembaga atau badan pendanaan untuk penelitian ini.

Konflik Kepentingan. Penulis menyatakan tidak ada konflik kepentingan.

Informasi Tambahan. Tidak ada informasi tambahan dalam artikel ini.

\section{Daftar Pustaka}

[1] S. I. Imelda, "Faktor-Faktor Yang Mempengaruhi Terjadinya diabetes Melitus di Puskesmas Harapan Raya Tahun 2018," SCJ, vol. 8, no. 1, pp. 28-39, May 2019, doi: 10.35141/scj.v8i1.406.

[2] N. C. Schaper, J. J. Van Netten, J. Apelqvist, B. A. Lipsky, K. Bakker, and on behalf of the International Working Group on the Diabetic Foot (IWGDF), Prevention and management of foot problems in diabetes: a Summary Guidance for Daily Practice 2015, based on the IWGDF Guidance Documents: Prevention and Management of Foot Problems in Diabetes, vol. 32. John Wiley \& Sons, Ltd, 2016.

[3] S. A. Bus et al., "Effect of Custom-Made Footwear on Foot Ulcer Recurrence in Diabetes: A multicenter randomized controlled trial," Diabetes Care, vol. 36, no. 12, pp. 4109-4116, Dec. 2013, doi: 10.2337/dc13-0996.

[4] A. A. H. Sulistyo, "MANAGEMENT OF DIABETIC FOOT ULCER: A LITERATURE REVIEW," Jurnal Keperawatan Indonesia, vol. 21, no. 2, pp. 84-93, Aug. 2018, doi: 10.7454/jki.v21i2.634.

[5] K. J. Williams, V. Sounderajah, B. Dharmarajah, A. Thapar, and A. H. Davies, "Simulated Wound Assessment Using Digital Planimetry versus Three-Dimensional Cameras: Implications for Clinical Assessment," Annals of Vascular Surgery, vol. 41, pp. 235-240, May 2017, doi: 10.1016/j.avsg.2016.10.029.

[6] L. B. Jørgensen, J. A. Sørensen, G. B. Jemec, and K. B. Yderstraede, "Methods to assess area and volume of wounds - a systematic review: Review of methods to assess wound size," Int Wound J, vol. 13, no. 4, pp. 540-553, Aug. 2016, doi: 10.1111/iwj.12472.

[7] P. Foltynski, "Ways to increase precision and accuracy of wound area measurement using smart devices: Advanced app Planimator," PLoS ONE, vol. 13, no. 3, p. e0192485, Mar. 2018, doi: 10.1371/journal.pone.0192485.

[8] K. S. Babu, K. Y. B. Ravi, and S. Sabut, "An improved watershed segmentation by flooding and pruning algorithm for assessment of diabetic wound healing," in 2017 2nd IEEE International Conference on Recent Trends in Electronics, Information \& Communication Technology (RTEICT), Bangalore, May 2017, pp. 679-683, doi: 10.1109/RTEICT.2017.8256683. 
[9] M. F. Ahmad Fauzi, I. Khansa, K. Catignani, G. Gordillo, C. K. Sen, and M. N. Gurcan, "Computerized segmentation and measurement of chronic wound images," Computers in Biology and Medicine, vol. 60, pp. 74-85, May 2015, doi: 10.1016/j.compbiomed.2015.02.015.

[10] S. Niu, Q. Chen, L. de Sisternes, Z. Ji, Z. Zhou, and D. L. Rubin, "Robust noise region-based active contour model via local similarity factor for image segmentation," Pattern Recognition, vol. 61, pp. 104 119, Jan. 2017, doi: 10.1016/j.patcog.2016.07.022.

[11] W. Xiong et al., "Foreground-Aware Image Inpainting," in 2019 IEEE/CVF Conference on Computer Vision and Pattern Recognition (CVPR), Long Beach, CA, USA, Jun. 2019, pp. 5833-5841, doi: 10.1109/CVPR.2019.00599.

[12] L. Wang, Y. Chang, H. Wang, Z. Wu, J. Pu, and X. Yang, "An active contour model based on local fitted images for image segmentation," Information Sciences, vol. 418-419, pp. 61-73, Dec. 2017, doi: 10.1016/j.ins.2017.06.042.

[13] Y. A. Gerhana, W. B. Zulfikar, A. H. Ramdani, and M. A. Ramdhani, "Implementation of Nearest Neighbor using HSV to Identify Skin Disease,” IOP Conf. Ser.: Mater. Sci. Eng., vol. 288, p. 012153, Jan. 2018, doi: 10.1088/1757-899X/288/1/012153.

[14] R. B. Shi, J. Qiu, and V. Maida, "Towards algorithm-enabled home wound monitoring with smartphone photography: A hue-saturation-value colour space thresholding technique for wound content tracking," Int Wound J, vol. 16, no. 1, pp. 211-218, Feb. 2019, doi: 10.1111/iwj.13011.

[15] V. Grandi et al., "ALA-PDT exerts beneficial effects on chronic venous ulcers by inducing changes in inflammatory microenvironment, especially through increased TGF-beta release: A pilot clinical and translational study," Photodiagnosis and Photodynamic Therapy, vol. 21, pp. 252-256, Mar. 2018, doi: 10.1016/j.pdpdt.2017.12.012.

[16] R. C. op 't Veld et al., "Thermosensitive biomimetic polyisocyanopeptide hydrogels may facilitate wound repair," Biomaterials, vol. 181, pp. 392-401, Oct. 2018, doi: 10.1016/j.biomaterials.2018.07.038.

[17] E. Sirazitdinova and T. M. Deserno, "System design for 3D wound imaging using low-cost mobile devices," Orlando, Florida, United States, Mar. 2017, p. 1013810, doi: 10.1117/12.2254389.

[18] A. Gupta, "Real time wound segmentation/management using image processing on handheld devices," JCM, vol. 17, no. 2, pp. 321-329, Apr. 2017, doi: 10.3233/JCM-170706.

[19] B. Bozorgtabar, S. Sedai, P. K. Roy, and R. Garnavi, "Skin lesion segmentation using deep convolution networks guided by local unsupervised learning," IBM J. Res. \& Dev., vol. 61, no. 4/5, p. 6:1-6:8, Jul. 2017, doi: 10.1147/JRD.2017.2708283.

[20] R. Mishra and O. Daescu, "Deep learning for skin lesion segmentation," in 2017 IEEE International Conference on Bioinformatics and Biomedicine (BIBM), Kansas City, MO, Nov. 2017, pp. 1189-1194, doi: 10.1109/BIBM.2017.8217826.

[21] F. Li, C. Wang, X. Liu, Y. Peng, and S. Jin, "A Composite Model of Wound Segmentation Based on Traditional Methods and Deep Neural Networks," Computational Intelligence and Neuroscience, vol. 2018, pp. 1-12, May 2018, doi: 10.1155/2018/4149103.

[22] E. Hamuda, B. Mc Ginley, M. Glavin, and E. Jones, "Automatic crop detection under field conditions using the HSV colour space and morphological operations," Computers and Electronics in Agriculture, vol. 133, pp. 97-107, Feb. 2017, doi: 10.1016/j.compag.2016.11.021.

[23] M. Kumar and S. R. Jindal, "Fusion of RGB and HSV colour space for foggy image quality enhancement," Multimed Tools Appl, vol. 78, no. 8, pp. 9791-9799, Apr. 2019, doi: 10.1007/s11042018-6599-8.

[24] M. Jawahar, L. J. Anbarasi, S. G. Jasmine, and M. Narendra, "Diabetic Foot Ulcer Segmentation using Color Space Models," in 2020 5th International Conference on Communication and Electronics Systems (ICCES), COIMBATORE, India, Jun. 2020, pp. 742-747, doi: 10.1109/ICCES48766.2020.9138024.

[25] M. Elmogy, A. Khalil, A. Shalaby, A. Mahmoud, M. Ghazal, and A. El-Baz, "Chronic Wound Healing Assessment System Based on Color and Texture Analysis," in 2019 IEEE International Conference on Imaging Systems and Techniques (IST), Abu Dhabi, United Arab Emirates, Dec. 2019, pp. 1-5, doi: 10.1109/IST48021.2019.9010586.

[26] Y. Li, J. Zhang, P. Gao, L. Jiang, and M. Chen, "Grab Cut Image Segmentation Based on Image Region," in 2018 IEEE 3rd International Conference on Image, Vision and Computing (ICIVC), Chongqing, Jun. 2018, pp. 311-315, doi: 10.1109/ICIVC.2018.8492818.

[27] C. Rother, V. Kolmogorov, and A. Blake, "'GrabCut' - Interactive Foreground Extraction using Iterated Graph Cuts," p. 6. 